\title{
Are the benefits of statins a class effect?
}

\section{James M. Wright}

ß See related article page 1187

I $\mathrm{n}$ general we have to be cautious about basing prescribing decisions on the results of cohort studies. When physicians prescribed hormone replacement therapy to postmenopausal women in the 1990s for the prevention of coronary artery disease, they made a mistake. That is because their decision was based on the Nurses' Health cohort study $^{1}$ and other cohort studies. ${ }^{2}$ In 2002 the Women's Health Initiative randomized trial ${ }^{3}$ demonstrated that, compared with placebo, combined estrogen-progestin therapy increased the risk of coronary artery disease (hazard ratio [HR] 1.29, 95\% confidence interval [CI] 1.02-1.63).

In some instances, however, cohort studies provide accurate findings, and it is reasonable to base prescribing decisions on them. I believe that the cohort analysis in this issue (page 1187) is one of those instances. The article by Zhou and associates ${ }^{4}$ reports on the effectiveness of 5 statins in elderly patients in 3 Canadian provinces and provides good evidence that the important outcomes are the same for the different statins. This represents evidence in favour of a class effect for the statins. The reasons the findings of this cohort analysis are likely telling us the truth include the following: First, the 5 well-defined cohorts are remarkably similar in terms of comorbidities at baseline (see Table 1 in their article). Second, the outcomes of death and recurrent acute myocardial infarction (AMI) are easily identified in administrative databases and are those that matter to patients. Third, it is unlikely that there would be selection bias by physicians in choosing a statin. Fourth, the study was large enough to provide a precise estimate of the treatment effect (the $95 \%$ CIs are narrow and within a $10 \%$ range for pravastatin and simvastatin compared with atorvastatin). Finally, the results are consistent with those of indirect comparisons of different statins based on a systematic review of placebo-controlled randomized trials. ${ }^{5}$

The study by Zhou and associates provides critical information about how statins are prescribed in Quebec, Ontario and British Columbia. I was struck by the following findings: Only $33 \%$ of the patients with an AMI had filled a prescription for a statin within 90 days of discharge from hospital. Persistence with the statin was high among those who received it; only $11 \%$ who had filled a prescription for a statin stopped statin treatment during a median follow-up of 2.3 years. The median doses of statins prescribed were all at the lower end of the dose range (atorvastatin $10 \mathrm{mg}$, pravastatin $20 \mathrm{mg}$, simvastatin $20 \mathrm{mg}$, lovastatin $20 \mathrm{mg}$ and fluvastatin $20 \mathrm{mg}$ ), which indicates that most physicians are conservative and cautious in prescribing these drugs. Very few patients had a dose increase or decrease.

I disagree with Zhou and associates on one important point. They conclude that the statin doses were similar based on cholesterol-lowering equivalents. That statement implies that the average magnitude of cholesterol-lowering effect in the 5 cohorts was similar. The authors mention that, since they did not have data on cholesterol measurements, it was impossible to directly answer that question. However, they ignore the fact that the median doses of the statins prescribed differ considerably in their ability to lower cholesterol. According to findings of a systematic review by Law and colleagues, ${ }^{6}$ the expected average proportional reduction in low-density lipoprotein (LDL) cholesterol for the median doses taken by the patients in the study by Zhou and associates would be $37 \%$ for $10 \mathrm{mg}$ of atorvastatin, $24 \%$ for $20 \mathrm{mg}$ of pravastatin, $32 \%$ for $20 \mathrm{mg}$ of simvastatin, $29 \%$ for $20 \mathrm{mg}$ of lovastatin and $21 \%$ for $20 \mathrm{mg}$ fluvastatin. This study, therefore, demonstrates that the benefit of statins is independent not only of which statin is prescribed, but also of the percentage reduction in LDL cholesterol over the range of $21 \%-37 \%$. This confirms the findings in the largest statin trial to date, the Heart Protection Study, where the benefit expressed as relative risk (RR) was the same for the 3 tertiles of patients with different reductions in LDL cholesterol before randomization: less than $38 \%$ reduction (RR $0.78,95 \%$ CI $0.71-0.85$ ), 38\%-47\% reduction (RR $0.79,95 \%$ CI $0.73-$ 0.87 ), and $48 \%$ or greater reduction (RR $0.79,95 \%$ CI $0.72-0.86){ }^{7}$

The results of $Z$ hou and associates should not be extrapolated to the setting of primary prevention, where it is unclear whether the benefits of statins outweigh the harms. ${ }^{8}$ The results probably can be extrapolated to patients with coronary artery disease other than a recent AMI and to patients with cerebrovascular disease or peripheral vascular disease. In the Heart Protection Study the treatment benefit of simvastatin was similar among patients with prior coronary artery disease (RR $0.79,95 \%$ CI $0.74-0.85$ ), those with prior cerebrovascular disease (RR $0.79,95 \%$ CI $0.66-0.95)$ and those with prior peripheral vascular disease (RR $0.81,95 \%$ CI $0.71-0.91)$. $^{7}$ It is also likely that the results are not specific for patients 65 years and older. In the Heart Protection Study the benefit among patients less than 65 years old (RR $0.77,95 \%$ CI $0.71-0.83$ ) was similar to that among older patients (RR $0.80,95 \%$ CI $0.75-0.85$ ). 
The only exception to this extrapolation is perhaps for patients with acute coronary syndrome. In the recently reported PROVE IT-TIMI 22 randomized controlled trial, ${ }^{2} 2$ statins were compared at different cholesterolreducing doses: at 30 days after the start of treatment, atorvastatin $80 \mathrm{mg}$ and pravastatin $40 \mathrm{mg}$ reduced LDL cholesterol by $51 \%$ and $22 \%$, respectively. At 2 years, the event rate of the composite outcome of death from any cause or major vascular event was lower with atorvastatin than with pravastatin (22.4\% v. 26.3\%; HR 0.84, 95\% CI 0.74-0.95). As can be appreciated by the wide confidence intervals and the fact that the findings from the PROVE IT-TIMI 22 trial contradict the evidence from the Heart Protection Study, these findings need to be confirmed.

Since in most settings of secondary prevention it does not appear to matter which statin is prescribed in terms of benefit, does it matter in terms of cost? In fact, the cost does vary widely depending on the statin, the dose and whether the tablets are split to reduce cost. Using 2005 BC Pharmacare data, I have compared the average cost of the most commonly used doses of statins in terms of whether the pills are taken whole or whether larger-dose tablets are halved or quartered (Table 1). For whole pills, fluvastatin $20 \mathrm{mg}$ is the least costly. If patients are willing to cut larger-dose tablets into halves, simvastatin and pravastatin are the least costly;

Table 1: Average cost of the most frequently dispensed statin doses in British Columbia

\begin{tabular}{lcccc}
\hline & & \multicolumn{3}{c}{ Daily cost, \$* } \\
\cline { 3 - 5 } $\begin{array}{l}\text { Generic (brand) } \\
\text { name of statin }\end{array}$ & $\begin{array}{c}\text { Daily } \\
\text { dose, }\end{array}$ & $\begin{array}{c}\text { Whole tablet } \\
\text { or capsule }\end{array}$ & $\begin{array}{c}\text { Half } \\
\text { tablet }\end{array}$ & $\begin{array}{c}\text { Quarter } \\
\text { tablet }\end{array}$ \\
\hline Atorvastatin (Lipitor) & 10 & 1.80 & 1.10 & 0.60 \\
& 20 & 2.25 & 1.20 & 0.60 \\
Fluvastatin (Lescol) & 40 & 2.40 & 1.20 & NA \\
Lovastatin (Mevacor) & 20 & 0.85 & NA & NA \\
Simvastatin (Zocor) & 10 & 1.15 & 1.05 & NA \\
& 20 & 1.20 & 0.75 & 0.35 \\
Pravastatin (Pravachol) & 20 & 1.45 & 0.75 & 0.35 \\
Rosuvastatin (Crestor) & 10 & 1.45 & 0.75 & NA \\
\hline Note: NA = not applicable (fluvastatin capsules cannot be cut; required tablet sizes are not \\
available).
\end{tabular}

those willing to cut tablets into quarters will find that simvastatin is a bargain. Since the costs of drugs do not vary greatly between provinces, the costs in other provinces will be similar to those in British Columbia.

In summary, this is an important cohort study that demonstrates that, among patients who have experienced an AMI, the incidence of recurrent AMI or death from any cause is similar for 5 different statins at doses that achieve different magnitudes of LDL reduction. This evidence provides physicians with an opportunity to reduce costs to patients and the health care system while still achieving optimal health outcomes for their patients.

From the Departments of Pharmacology and Therapeutics and of Medicine, University of British Columbia, Vancouver, BC

Competing interests: None declared.

\section{References}

1. Stampfer MJ, Colditz GA, Willett WC, Manson JE, Rosner B, Speizer FE, et al. Postmenopausal estrogen therapy and cardiovascular disease. Ten-year follow-up from the nurses' health study. N Engl 7 Med 1991;325:756-62.

2. Grady D, Rubin SM, Petitti DB, Fox CS, Black D, Ettinger B, et al. Hormone therapy to prevent disease and prolong life in postmenopausal women. Ann Intern Med 1992;117:1016-37.

3. Rossouw JE, Anderson GL, Prentice RL, LaCroix AZ, Kooperberg C, Stefanick ML, et al; Writing Group for the Women's Health Initiative Investigators. Risks and benefits of estrogen plus progestin in healthy postmenopatus women: principal results from the Women's Health Initiative randomized controlled trial. FAMA 2002;288:321-33.

4. Zhou Z, Rahme E, Abrahamowicz M, Tu JV, Eisenberg MJ, Humphries K, et al. Effectiveness of statins for secondary prevention in elderly patients after acute myocardial infarction: an evaluation of class effect. CMAf 2005;172(9): 1187-94.

5. Vrecer M, Turk S, Drinovec J, Mrhar A. Use of statins in primary and secondary prevention of coronary heart disease and ischemic stroke. Meta-analysis of randomized trials. Int 7 Clin Pharmacol Ther 2003;41:567-77.

6. Law MR, Wald NJ, Rudnicka AR. Quantifying effect of statins on low density lipoprotein cholesterol, ischaemic heart disease, and stroke: systematic review and meta-analysis. BM7 2003;326(7404):1423.

7. Heart Protection Study Collaborative Group. MRC/BHF Heart Protection Study of cholesterol lowering with simvastatin in 20536 high-risk individuals: a randomized placebo-controlled trial. Lancet 2002;360:7-22.

8. Therapeutics Initiative. Do statins have a role in primary prevention? Ther Letter 2003;48:1-2.

9. Cannon CP, Braunwald E, McCabe CH, Rader DJ, Rouleau JL, Belder R, et al; Pravastatin or Atorvastatin Evaluation and Infection Therapy-Thrombolysis in Myocardial Infarction 22 Investigators. Intensive versus moderate lipid lowering with statins after acute coronary syndromes. $N$ Engl $7 \mathrm{Med}$ 2004:350:1495-504

Correspondence to: Dr. James M. Wright, Departments of Pharmacology and Therapeutics and of Medicine, 2176 Health Sciences Mall, University of British Columbia, Vancouver BC V6T 1Z3; jmwright@interchange.ubc.ca 